\title{
Evaluation of Sensorial and Antimicrobial Effects of Cumin on Cottage Cheese
}

\author{
Dereje Getahun $^{1^{*}}$, Hawi Tolera ${ }^{1}$, Simegn Serka ${ }^{2}$ \\ ${ }^{1}$ School of Nutrition and Food Science, Hawassa University, Ethiopia \\ ${ }^{2}$ Department of Chemistry, Hawassa University, Ethiopia
}

\begin{abstract}
This study was conducted to investigate the effect of different levels of cumin powder on microbial and sensorial characteristics of cottage cheese. Each cheese sample $(60 \mathrm{~g})$ was packed into polyethylene plastic bag and put into containers. The containers were tightly closed and stored at room temperature for one week. Sensory evaluation was carried out at zero-day and microbial analysis was carried out at 0, 3 and 5 days interval. All sensory attributes were affected by cumin powder concentration. Cumin powder showed a strong antimicrobial effect and all sensory attributes were affected by cumin powder concentration. Treatment of cheese with $1 \%$ cumin powder is recommended for antimicrobial and sensorial quality.
\end{abstract}

Keywords: Cottage cheese; Cumin powder; Antimicrobial effect; Sensory attributes

\section{INTRODUCTION}

Cheese is a food derived from different types of milk that are produced in a wide range of flavors and textures. There are several types of cheeses which are grouped according to different criteria such as length of aging, texture, manufacturing method, fat content, animal milk and country [1]. According to an ancient legend, cheese was discovered several thousand years ago by an Arabian merchant who placed milk in a pouch made from a sheep's stomach as he set out for a days' journey across the desert [2]. The rennet in the lining of the pouch, combined with the heat of the sun, caused the milk to separate into the curd of cheese and thin liquid now called whey.

Cottage cheese is unripe, soft and coagulated curd cheese type [3]. These cheeses do not undergo curing and are generally the result of acid coagulation of the milk. The composition, as well as processing steps, provides specific product texture. Compared to most other cheeses, cottage cheese provides less calcium. In the manufacturing of cottage cheese, $50 \%$ to $75 \%$ of milk's calcium is removed when the whey is drained. These cheeses are high in protein, generally low in fat and a good source of riboflavin. It provides nutrition in the form of vitamins, minerals and a high-quality source of protein. Cheese has important nutrient for humans especially under conditions where other animal proteins are not available [4].
Cottage cheese has higher moisture content when compared to hard cheese and have short shelf life due to microbial spoilage [5]. The use of cumin and its volatile compounds as natural preservatives in cheese as an alternative to the use of chemical additives to increase the shelf life and to inhibit microbial spoilage of cheese. In Ethiopia, most of the time cheese produced at home traditionally. Due to poor handling practice, utensil used poor manufacturing practice during processing, transportation, and storage the cheese might be spoiled due to its susceptibility for microbes. According to Ashenafi M [6], milk and milk product manufactured under traditional systems generally have poor qualities and do not meet the acceptable quality requirements set by various regulatory agencies. Cumin seed has important antimicrobial activities against different strains. The alcoholic and aqueous extract of cumin inhibit the growth of some gram-positive and gram-negative pathogenic bacteria [7]. Cumin contains cumin Aldehydes and pyrazines which act as stimulant, anti-fungal, and antimicrobial properties. The essential oil of cumin exhibits strong antimicrobial activity against Escherichia coli, Staphylococcus aureus, and Listeria monocytogenes. The report showed that cumin oil indicates fungicidal and antibacterial activity due to the cumin Aldehydes content $[8,9]$.

Correspondence to: Dereje Getahun, School of Nutrition and Food Science, Hawassa University, Ethiopia, E-mail: derew36@gmail.com

Received: August 03, 2019; Accepted: September 23, 2019; Published: September 30, 2019

Citation: Getahun D, Tolera H, Serka S (2019) Evaluation of Sensorial and Antimicrobial Effects of Cumin on Cottage Cheese. J Food Process Technol 10:813. doi: 10.35248/2157-7110.19.10.813

Copyright: (C) 2019 Getahun D, et al. This is an open-access article distributed under the terms of the Creative Commons Attribution License, which permits unrestricted use, distribution, and reproduction in any medium, provided the original author and source are credited. 


\section{MATERIALS AND METHODS}

\section{Material collection}

Fresh cow milk, cumin powder (Cuminum cyminum L. (Apiaceae)) and lemon were purchased from Hawassa local market.

\section{Methods}

Cheese preparation: Cheese was prepared from cow's fresh milk which was purchased from Hawassa local market. The received four liters milk was added in to eight different beakers each contains $500 \mathrm{ml}$ and lemon juice were added at the rate of 7.5 $\mathrm{ml}$ per beaker $(500 \mathrm{ml})$; the milk was stirred for $2-3$ minutes then put in water bath at $40^{\circ} \mathrm{C}$; the temperature was raised gradually to $65^{\circ} \mathrm{C}$ and left for coagulation. After 5 hours the coagulated milk was separated from the whey and divided into four equal parts; the first treatment is the control without addition of cumin powder. To the second, third and fourth treatments: $1 \%, 2 \%$ and $3 \%$ cumin powder concentration were added respectively. Each cheese samples $(60 \mathrm{~g})$ were packed into polyethylene plastic bags and put into container. The containers were tightly closed and stored at room temperature for one week. Sensory evaluation was carried out at zero-day [10] and microbial analysis was carried out at zero, 3 and 5 days interval [1].

Microbiological analysis: The total microbial count, yeast, and mold were estimated using the procedure that had been followed by American public health associations [11]. Cheese samples were taken aseptically from each replication (at 0, 3 and 5 days) using pre-sterilized pipette and immediately subjected to serial dilution. Sample $(1 \mathrm{ml})$ was serially diluted in $9 \mathrm{ml}$ of peptone water. The dilutions were done in the range of $10^{-1}$ to $10^{-7}$ series of test tubes for estimation of total aerobic bacteria. The sample of $0.1 \mathrm{ml}$ was taken from the test tube aseptically using discrete pipette and plated on plate count agar [1]. Finally all plates were incubated at $30^{\circ} \mathrm{C}$ for 2 days. The growth in bacteria was inspected after 2 days; colonies were counted using standard colony counter. For the estimation of Yeast and Mold Count (YMC), the sample of $0.1 \mathrm{ml}$ was aseptically taken from the test tube using a sterilized discrete pipette and was plated on yeast extract chloramphenicol glucose agar according to American public health associations [11]. Then it was placed inverted and incubated at $25^{\circ} \mathrm{C}$ for 5 days. The growth in yeast was inspected after 3 days and non-growth plates were incubated for two days more to complete the recommended incubation period.

Sensory evaluation: A total of 15 consumer-oriented panelists were involved in the sensory evaluation from ACA (Hawassa University) students. The attributes used for sensory evaluation were color, flavor, texture, taste and overall acceptance. Sensory evaluation was taken place by using a 5 point hedonic scale (5=like very much, 4=like moderately, 3=neither like nor a dislike, 2 =dislike moderately, $1=$ dislike very much).

Experimental design and data analysis: Randomized complete block designs, RCBD, was used to investigate the effect of cumin concentration on sensory attributes of cheese. A factorial design was used for microbial analysis. The data collected from the sensory and microbial analysis was subjected to analysis of variance (ANOVA) using SAS version 9.1. Results were expressed as mean \pm standard deviation.

\section{RESULTS AND DISCUSSION}

Data shown in Table 1 indicates that all sensory attributes were affected by cumin powder concentrations. As a result flavor, texture, color, and taste mean scores of the cheese are significantly different. The mean score of control cheese is higher than that of cheese samples which are treated with cumin powder. These results are not similar to those found by Ibrahim et al. [1] and Omer [10]. This might be due to the used different form of cumin. In this research cumin powder was used while they used cumin oil. The mean scores of untreated cheese samples have the highest. $1 \%$ cumin powder treated samples have highest taste mean scores next to the untreated samples. Untreated samples have the highest flavor mean score among all the samples considered. However, samples with $1 \%$ and $3 \%$ cumin powder had comparable flavor mean scores and not significantly different. Untreated cheese samples had the highest color mean score, cheese treated with $2 \%$ and $3 \%$ cumin were not significantly different in color and texture mean scores among all the samples. $1 \%$ and $3 \%$ cumin treated samples did not have marked significant difference in texture. The overall consumer acceptability means values ranged from 4.30 to 2.7. Untreated cheese samples have the highest overall consumer acceptability mean score. $1 \%$ cumin powder has comparable acceptance mean scores with the untreated sample.

Table 1: Effect of Cumin powder on the sensory characteristics of cottage cheese.

\begin{tabular}{llllll}
\hline Sample & Color & Texture & Flavor & Taste & Overall acceptability \\
\hline $0 \%$ cumin & $4.56 \pm 0.67^{\mathrm{a}}$ & $4.10 \pm 1.12^{\mathrm{a}}$ & $3.93 \pm 0.90^{\mathrm{a}}$ & $4.1 \pm 0.92^{\mathrm{a}}$ & $4.30 \pm 0.79^{\mathrm{a}}$ \\
\hline $1 \%$ cumin & $3.56 \pm 0.7^{\mathrm{b}}$ & $3.06 \pm 0.94^{\mathrm{b}}$ & $3.03 \pm 1.03^{\mathrm{b}}$ & $3.0 \pm 0.83^{\mathrm{b}}$ & $3.46 \pm 0.57^{\mathrm{b}}$ \\
\hline $2 \%$ cumin & $2.80 \pm 1.03^{\mathrm{c}}$ & $2.53 \pm 1.13^{\mathrm{c}}$ & $2.36 \pm 0.86^{\mathrm{c}}$ & $2.7 \pm 0.87^{\mathrm{b}}$ & $2.80 \pm 0.71^{\mathrm{c}}$ \\
\hline $3 \%$ cumin & $2.60 \pm 0.93^{\mathrm{c}}$ & $2.86 \pm 0.81^{\mathrm{bc}}$ & $2.76 \pm 1.10^{\mathrm{bc}}$ & $2.6 \pm 0.93^{\mathrm{b}}$ & $2.7 \pm 0.79^{\mathrm{c}}$ \\
\hline
\end{tabular}


$a b c=$ Means bearing different superscripts within columns are significantly different $(p<0.05)$

Concerning the microbiological quality of cheeses, cumin powder showed a strong antimicrobial effect. It is natural preservative due to its essential oils and weak organic acid. Cheese which is treated with cumin powder leading to reduction of the microbial groups in treated cheeses, compared with initial count ( 0 day). These findings are similar to the results obtained by Dormans and Deans [12] and Ibrahim et al. [1], who reported that essential oils of cumin have strong antimicrobial effect.

The antibacterial activity of cumin could be attributed to a number of polyphenolic compounds including gallic acid, protocatechuic acid, caffeic acid, ellagic acid, ferulic acid, as well as flavonoid compounds such as quercetin and kaempferol [13]. They explained that the antibacterial activity of flavonoid was attributed to the inhibition of the synthesis of DNA and RNA and other related macromolecules. Further, it was found that phenolic compounds with more than three $3-\mathrm{OH}$ possess antibacterial activity [1] (Table 2).

Table 2: Effect of Cumin powder on the logarithmic total bacterial count in cottage cheese.

\begin{tabular}{|c|c|c|c|c|}
\hline \multirow{2}{*}{ Sample } & \multicolumn{4}{|l|}{ TBC } \\
\hline & 0 day & 3 day & 5 day & Total group \\
\hline $0 \%$ cumin & $6.3885 \pm 0.12374$ & $7.2085 \pm 0.18880$ & $7.2625 \pm 0.10112$ & $7.61986^{\mathrm{a}}$ \\
\hline $1 \%$ cumin & $6.1025 \pm 0.31183$ & $5.9615 \pm 0.06010$ & $5.8850 \pm 0.04808$ & $6.01636^{\mathrm{b}}$ \\
\hline $2 \%$ cumin & $5.9765 \pm 0.25102$ & $5.8180 \pm 0.32103$ & $5.6065 \pm 0.16193$ & $5.73686^{c}$ \\
\hline $3 \%$ cumin & $5.8815 \pm 0.95076$ & $5.7555 \pm 0.20294$ & $5.4785 \pm 0.10960$ & $5.1020^{d}$ \\
\hline
\end{tabular}

$a b c=$ Means bearing different superscripts within columns are significantly different $(p<0.05)$

Table 3: Effect of Cumin powder on yeast and mold in cottage cheese.

\begin{tabular}{|c|c|c|c|c|}
\hline \multirow{2}{*}{ Sample } & \multicolumn{4}{|l|}{ Yeast and Mold } \\
\hline & 0 day & 3 day & 5 day & Total group \\
\hline 0\% cumin & $4.4415 \pm 0.63427$ & $4.4695 \pm 0.04455$ & $4.5070 \pm 0.13294$ & $4.40606^{\mathrm{a}}$ \\
\hline $1 \%$ cumin & $3.8150 \pm 0.03253$ & $3.7955 \pm 0.00495$ & $3.7685 \pm 0.21708$ & $3.83036^{b}$ \\
\hline $2 \%$ cumin & $3.765 \pm 0.08132$ & $3.7510 \pm 0.02404$ & $3.6635 \pm 0.10960$ & $3.79306^{\mathrm{b}}$ \\
\hline $3 \%$ cumin & $3.6620 \pm 0.19799$ & $3.5370 \pm 0.07778$ & $3.4925 \pm 0.08697$ & $3.7672^{\mathrm{b}}$ \\
\hline
\end{tabular}

$a b c=$ Means bearing different superscripts within columns are significantly different $(p<0.05)$

Cumin has an excellent antimicrobial effect on total bacterial count, yeast, and mold. It inhibits the growth of both. The growth of bacteria increased on treatment one ( $0 \%$ cumin) during storage time. While cheese which is treated with cumin indicates low growth of bacteria, yeast, and mold than control one. T4 (3\% cumin) has higher inhibitory effect than cheese treated with $1 \%$ and $2 \%$ cumin (Table 3 ).

\section{CONCLUSION AND RECOMMENDATION}

\section{Conclusion}

Cumin powder showed a strong antimicrobial effect. Cheese which was treated with cumin powder leading to reduction of the microbial groups in treated cheeses, compared with untreated cheese samples. All sensory attribute is affected by cumin powder concentration. Cheese which was treated with $1 \%$ cumin powder received the highest consumer acceptability mean scores compared with other treatments. 


\section{Recommendation}

Treatment of cheese with $1 \%$ cumin powder is recommended for antimicrobial and sensorial quality. Further study is recommended on Physico-chemical and proximate analysis of cheese on the effect of cumin powder.

\section{ACKNOWLEDGMENT}

The authors would like to thank Hawassa University, College of Agriculture, School of Nutrition and Food Science.

\section{REFERENCES}

1. Ibrahim JI, Abdel-Hakiem EH. Quality improvement of Damiet -ta cheese using some spices extract. Assiut Vet Med J. 2015;61:147.

2. International Dairy Food Association, dairy facts, (2004 Edition), IDHSA, Washington, D.C., September 2004.

3. Preservatives in food (Amendment) Regulation. Preservatives and antioxidants user guidelines. 2008:9.

4. Mistry KF. Cheese and Fermented milk foods; Brooktondale: Kosikowski and Associates. 1997.

5. Rhea F. Microbiology Handbook dairy products, 1st edition1, UK: Leather head food international ltd. 2009.
6. Ashenafi M. The Microbiology of Ethiopian foods and beverages; A review, SENE. Ethiop J Biol Sci. 2002;5(2):189-245.

7. Motamedifar M, Haghighati G, Yousefi Arvand A. The study of the effect of cumin seeds extracts on some pathogenic bacterial agents. BMJ Publishing Group. 2012.

8. Gachkar L, Davood Y, Mohammad BR, Masood T, Shakiba AA, Iraj R. Chemical and biological characteristics of Cuminum Cyminum and Rosmarinus officinalis essential oils. Food Chem. 2007;102(3):898-904.

9. Lawrence BM. Progress in essential oils; Perfumer and Flavorist. 1992;17(4):42-44.

10. Omer IA. Effect of Cumin oil concentrations on chemical composition and sensory characteristics of Sudanese white cheese during ripening. Int J Curr Microbial App Sci. 2014;3:961-968.

11. American Public Health Association (APHA). Compendium of methods for the microbiological examination of food, 17th ed. Washington D.C, USA. 2004

12. Dormans HJ, Deans SG. Antimicrobial agents from plants: antimicrobial activity of plant volatiles oil. J Al Microbiol. 2000;88:308-316.

13. Ani V, Varadaraj MC, Akhilender Naidu K. Antioxidant and antibacterial activities of polyphenolic compounds from bitter cumin (Cuminum nigrum L.). Eur Food Res Technol. 2006;224:109-115. 